\title{
INCLUSÃO, INTERCULTURALIDADE E INOVAÇÃO PEDAGÓGICA NOS CURSOS DE LICENCIATURA DO INSTITUTO FEDERAL DE EDUCAÇÃO, CIÊNCIA E TECNOLOGIA CATARINENSE
}

\author{
INCLUSIÓN, INTERCULTURALIDAD E INNOVACIÓN PEDAGÓGICA EN LOS \\ CURSOS DE LICENCIATURA DEL INSTITUTO FEDERAL DE EDUCAÇÃO \\ CIÊNCIA E TECNOLOGIA CATARINENSE
}
INCLUSION, INTERCULTURALITY AND PEDAGOGICAL INNOVATION AT CATARINENSE FEDERAL INSTITUTE OF EDUCATION, SCIENCE AND TECHNOLOGY'S GRADUATION COURSES

\author{
Filomena Lucia Gossler Rodrigues da SILVA ${ }^{1}$ \\ Sonia Regina de Souza FERNANDES ${ }^{2}$ \\ Anelise Nascimento LANGE ${ }^{3}$
}

RESUMO: Este texto apresenta os resultados de uma pesquisa realizada no Instituto Federal de Educação, Ciência e Tecnologia Catarinense que investigou em que medida a inovação pedagógica, a interculturalidade e a inclusão estão presentes nos projetos pedagógicos dos Cursos de Licenciatura da referida instituição. Metodologicamente, este estudo se caracteriza como de abordagem qualitativa, contemplando análise documental e pesquisa bibliográfica. Entre os resultados do estudo estão o aprofundamento da discussão acerca dos conceitos de inclusão, interculturalidade e inovação pedagógica, a apresentação de um mapeamento das disciplinas que contemplam os conceitos mencionados, bem como uma síntese dos objetivos e perfis de egressos dos licenciandos.

PALAVRAS-CHAVE: Licenciatura. Inclusão. Interculturalidade. Inovação Pedagógica.

RESUMEN: Este texto presenta los resultados de una investigación realizada en el Instituto Federal de Educação, Ciência e Tecnologia Catarinense que investigó en qué medida la innovación pedagógica, la interculturalidad y la inclusión están presentes en los proyectos pedagógicos de los Cursos de Licenciatura de esta institución. Metodológicamente se caracteriza de abordaje cualitativo contemplando análisis documental e investigación bibliográfica. Entre los resultados están la profundización de la discusión sobre los conceptos de inclusión, interculturalidad e innovación

\footnotetext{
1 Instituto Federal de Educação, Ciência e Tecnologia Catarinense (IFC), Camboriú - SC - Brasil. Professora de Educação Básica, Técnica e Tecnológica/Departamento de Ensino. ORCID: https://orcid.org/0000-0002-8275-7714. E-mail: filomena.silva@ifc.edu.br

2 Instituto Federal de Educação, Ciência e Tecnologia Catarinense (IFC), Camboriú - SC - Brasil. Professora de Educação Básica, Técnica e Tecnológica/Departamento de Ensino. ORCID: https://orcid.org/0000-0001-6788-6238. E-mail: sonia.fernandes@ifc.edu.br

3 Instituto Federal de Educação, Ciência e Tecnologia Catarinense (IFC), Camboriú - SC - Brasil. Acadêmica do curso de licenciatura em Pedagogia/Coordenação do Curso de Pedagogia. ORCID: https://orcid.org/0000-0001-8365-4154. E-mail: anelange@gmail.com
} 
pedagógica, la presentación de una cartografía de las disciplinas que contemplan los conceptos mencionados, así como una síntesis de los objetivos y los perfiles de egresados de los licenciandos.

PALABRAS CLAVE: Licenciatura. Inclusión. Interculturalidad. Innovación Pedagógica.

ABSTRACT: This text brings forward the results of a research carried out at Catarinense Federal Institute of Education, Science and Technology, which investigated the extent to which pedagogical innovation, interculturality and inclusion are present in the pedagogical projects of the Graduation Courses of this institution. Methodologically the following study is characterized as a qualitative approach contemplating documentary analysis and bibliographic research. Among the results of the study are the deepening of the discussion about the concepts of inclusion, interculturality and pedagogical innovation, the presentation of a mapping of the disciplines that contemplate the mentioned concepts, as well as a synthesis of the objectives and the alumni gaduation's profiles.

KEYWORDS: Graduation. Inclusion. Interculturality. Pedagogical innovation.

\section{Introdução}

O estudo que resultou neste artigo teve como propósito investigar em que medida a inovação pedagógica, a interculturalidade e a inclusão estão presentes nos projetos pedagógicos dos Cursos de Licenciatura do Instituto Federal de Educação, Ciência e Tecnologia Catarinense (IFC) e como tais temáticas contribuem para a formação integral dos licenciandos. $\mathrm{O}$ estudo decorre da preocupação em desenvolver processos inclusivos, interculturais e pedagogicamente inovadores na formação dos professores no IFC.

Embora tendo completado apenas uma década de criação em 29 de dezembro de 2008, por meio da Lei 11.892, de 29 de dezembro, os desafios colocados aos Institutos Federais são robustos. Vinculados à Secretaria de Educação Tecnológica (Setec) do Ministério da Educação (MEC), são interpelados a responder por demandas de formação que promovam tanto o desenvolvimento regional socialmente sustentável quanto a formação integral e emancipatória dos cidadãos. Tal compromisso tem dimensão verticalizada na formação dos sujeitos, ou seja, abrange desde a qualificação profissional, por meio de cursos de curta duração, e todas as formas de articulação da educação profissional com o ensino médio (integrado, concomitante e subsequente), até 
os cursos de graduação (tecnólogos, bacharelados e licenciaturas) e de pós-graduação (lato e stricto sensu).

No que se refere à formação de professores, o Plano de Desenvolvimento Institucional do Instituto Federal Catarinense - Blumenau (IFC, 2014) e o Acordo de Metas do IFC (BRASIL, 2008), alinhados aos objetivos dos Institutos Federais de Educação, têm realizado ações que visam alcançar a meta de ter pelo menos $20 \%$ das suas vagas destinadas à formação inicial (licenciaturas) e à formação continuada (programas especiais de formação pedagógica: atividades de extensão, cursos e programas de pós-graduação lato e stricto sensu).

Quanto à formação inicial dos professores, o IFC oferece cursos de licenciatura em Física, Matemática, Química, Pedagogia, Pedagogia do Campo e Ciências Agrícolas. Tendo em vista o compromisso assumido pela instituição no que diz respeito à oferta de cursos de licenciatura cuja concepção esteja atrelada e comprometida com a qualidade social referenciada dos processos educativos, a instituição realizou um amplo processo de rediscussão dos projetos pedagógicos dos cursos.

Uma das definições mais importantes do coletivo de professores e gestores dos cursos e da reitoria foi ter avançado no estabelecimento de um núcleo comum para os cursos de formação de professores, nos quais, conforme é possível verificar na discussão dos dados da pesquisa realizada, observa-se a presença de debates que envolvem a inclusão, a interculturalidade e a inovação pedagógica.

No que diz respeito à concepção de inclusão assumida neste trabalho, cumpre esclarecer que esta ultrapassa a ideia de inserir no contexto acadêmico políticas, culturas e práticas destinadas exclusivamente às pessoas com deficiência, como temos observado especialmente nos discursos de professores e gestores de instituições de ensino de um modo geral. Trata-se de pensar as políticas, a cultura e as práticas de modo a fazer com que se materializem nos documentos institucionais e nas ações desenvolvidas cotidianamente, a fim de não permitir qualquer discriminação no que diz respeito ao gênero, à etnia, à religião, à classe social, às condições físicas e psicológicas dos sujeitos envolvidos no processo educativo, entre outras.

Em que pese as discussões interculturais, é necessário dizer que tanto o conceito quanto as práticas interculturais são desconhecidas. Não é comum, no interior das instituições, abordar essa temática a partir desse conceito. Ainda que possa estar presente nas práticas, não se observa, no plano teórico, a presença do termo nos 
documentos orientadores das instituições, nem nos vocabulários dos profissionais que nela atuam.

Por fim, no que se refere ao conceito de inovação pedagógica, nos estudos realizados e nos diálogos estabelecidos, observamos que a primeira inferência que se faz quando este termo é mencionado tem relação com a utilização de tecnologias nos processos de ensino e aprendizagem. No entanto, aqui, toma-se a inovação pedagógica como o conjunto das ações que possam convergir para que os envolvidos no processo educativo venham a ter melhores condições para a construção dos saberes historicamente acumulados, de forma que as perspectivas interculturais e inclusivas possam ser incorporadas, transformando-se em políticas, culturas e práticas assumidas/vivenciadas pelos sujeitos envolvidos no processo educativo. Com isso pretende-se dizer que inovar pedagogicamente implica necessariamente construir condições, práticas e saberes que tenham como horizonte o desenvolvimento pleno dos seres humanos.

Estabelecidas essas considerações iniciais, localiza-se metodologicamente este estudo como de abordagem qualitativa, contemplando pesquisa bibliográfica e documental. No que diz respeito à revisão de literatura, foram priorizadas as produções teóricas convergentes com as concepções do Projeto do Observatório de Inclusão, Interculturalidade e Inovação Pedagógica (OIIIIPe), particularmente as publicações dos pesquisadores do referido observatório. Já a pesquisa documental foi realizada por meio da análise dos Projetos Político-Pedagógicos dos seguintes Cursos de Licenciatura do Instituto Federal Catarinense: Física (Rio do Sul e Concórdia), Matemática (Rio do Sul, Concórdia, Camboriú e Sombrio); Química (Araquari e Brusque); Pedagogia (Camboriú, Blumenau, Videira, Rio do Sul) Pedagogia do Campo (Abelardo Luz); e Ciências Agrícolas (Araquari).

No que tange à organização deste artigo, realiza-se inicialmente uma reflexão acerca das temáticas da inclusão, interculturalidade e inovação pedagógica para posteriormente serem apresentados e discutidos os dados de como essas temáticas estão presentes nos componentes curriculares das matrizes, nos objetivos e nos perfis de egresso dos cursos de licenciatura do IFC. 


\section{Inclusão, interculturalidade $\mathrm{e}$ inovação pedagógica: reflexões a partir das produções teóricas do OIIIIPe}

Em tempos de acirramento das desigualdades socioculturais, educacionais, econômicas, políticas e ideológicas, instituir e implementar ações de ensino, pesquisa e extensão que tenham como referência a perspectiva da qualidade social referenciada tem sido considerado um ato de resistência, no sentido de garantir o acesso aos direitos sociais básicos, a própria vivência da democracia e o exercício da cidadania plena, mundo afora e, particularmente, no Brasil. O que se tem observado por meio de estudos é que, nas últimas décadas, as temáticas inclusão, interculturalidade e inovação pedagógica têm sido objeto de investigação por parte de grupos de pesquisa, em universidades nacionais e internacionais, “[...] vislumbrando mudanças de paradigmas que contribuam para o desenvolvimento dos ambientes educacionais e atendam às necessidades humanas em contextos coletivos" (DAMÁZIO; SANTOS, 2018, p. 1227).

A partir do exposto pelas autoras, é possível observar que os conceitos de inclusão, de interculturalidade e de inovação pedagógica, entendidos em sua complexidade e profundidade, são potencialmente capazes de produzir mudanças nos ambientes educacionais, na perspectiva da formação integral dos estudantes.

Formar integralmente os estudantes nesta perspectiva implica desenvolver processos educativos e formativos que lhes oportunizem o desenvolvimento em todas as dimensões da vida (aspectos de ordem intelectual, física, emocional, social e cultural). Para alcançar esta dimensão de formação, é indispensável o desenvolvimento de práticas pedagógicas e de currículos que expressem claramente esta intenção.

No que diz respeito à inclusão, observa-se na produção teórica dos pesquisadores do OIIIIPe um alinhamento da compreensão sobre a inclusão que consiste no desenvolvimento de ações que se preocupam com a minimização de qualquer tipo de exclusão e também com a potencialização da participação das pessoas, ou seja, perpassa necessariamente pelo exercício da cidadania plena de todos os sujeitos (ALMEIDA et al., 2018, p. 150).

Nesse sentido, pode-se afirmar que a concepção de inclusão presente nas reflexões dos pesquisadores do OIIIIPe ultrapassa o senso comum da maioria da população, que a restringe ao desenvolvimento de políticas, culturas e práticas destinadas exclusivamente às pessoas com deficiências. A inclusão alcança, portanto, todas as ações que favoreçam a equidade no alcance dos direitos sociais básicos, como saúde, educação, moradia, alimentação, segurança, entre outros. 
No tocante à educação, compreende-se a inclusão como “[...] um processo de democratização da escola com o objetivo de diminuir as exclusões, agregando pessoas e reconhecendo a existência das diferenças. Inclusão está, portanto, baseada no acesso, permanência e participação do indivíduo" (ALMEIDA et al., 2018, p. 150).

Em que pese a compreensão da inclusão em um sentido mais amplo, entende-se que:

[...] os processos inclusivos se constituem como processos interculturais, para a criação de sociedades mais equitativas e igualitárias. Mas, sob os imperativos econômicos do modelo neoliberal de acumulação capitalista, a interculturalidade é tratada como estratégia de controle do conflito étnico, pela inclusão de grupos historicamente excluídos, de modo a manter a estabilidade social. (SILVA; FERNANDES; FLEURI, 2018, p. 1278).

Tendo presente tal compreensão, entende-se que as instituições de ensino, sejam elas de educação básica ou ensino superior, possuem um papel fundamental, no sentido de construir políticas e práticas interculturais, inclusivas e pedagogicamente inovadoras, de modo a contribuir para a construção de sociedades mais equitativas e igualitárias. No que diz respeito ao IFC, tem-se claro que, assumindo como missão institucional "Proporcionar educação profissional, atuando em Ensino, Pesquisa e Extensão, comprometida com a formação cidadã, a inclusão social, a inovação e o desenvolvimento regional" (IFC, 2014, p. 13), a instituição assume também o compromisso de construir projetos pedagógicos e desenvolver práticas pedagógicas que caminhem em direção à formação integral dos sujeitos e de uma sociedade mais justa.

De acordo com Damázio (2018, p. 132), “Tornar o espaço da escola e o da universidade brasileira inclusivos perpassa mudanças de paradigmas e exige novos 'jeitos' de fazer, ou seja, mudar a concepção da estrutura/funcionamento e as práxis pedagógicas". Tais mudanças poderão ocorrer com mais êxito quando as instituições e os profissionais que nela atuam assumirem o compromisso de desenvolver ações que se comprometam com uma educação inclusiva e intercultural. De acordo com Fleuri (2009, p. 33),

[...] a educação inclusiva busca partir de múltiplos contextos (culturais, subjetivos, sociais, ambientais), promover com as pessoas e grupos, simultânea e articuladamente, diferentes percursos, de modo a produzir múltiplos e complexos impactos sócio-educacionais [sic passim]. Este nos parece, justamente, o desafio intercultural que se coloca nas práticas de educação inclusiva: articular a diversidade de sujeitos, de contextos, de linguagens, de ações, de produções culturais, 
de modo que a potencialização de suas diferenças favoreça a construção de processos singulares e contextos sócio-educacionais críticos e criativos.

A partir do exposto por Fleuri (2009), observa-se a existência de uma relação bastante próxima entre inclusão e interculturalidade, uma vez que ambas exigem considerar as diversidades e as diferenças entre os sujeitos.

Quanto ao conceito de interculturalidade, a produção teórica dos pesquisadores pertencentes ao OIIIIPe revela que a origem de seus estudos nos reporta ao cenário europeu, no qual:

[...] inicialmente foi vista como solução para a inclusão de imigrantes na educação em caráter emergencial. Progressivamente avançada para a valorização das diferenças, a formação da identidade e a legitimação da cultura de origem de cada indivíduo, essa perspectiva proporciona não somente o fortalecimento da identidade, como também reconhece importância em considerar o contexto no qual o aluno encontra-se inserido. (CAPELLINI; MACENA, 2018, p. 165).

Tendo presente o exposto, compreende-se que se colocam no horizonte muitos desafios para vencer preconceitos e discriminações. Vale mencionar, contudo, que “[...] não é por acaso que concepções e hábitos tão arraigados na tradição sejam colocados em questão neste momento de nossa história. As mudanças no modo de pensar e de interagir decorrem de mudanças sociais e culturais profundas e radicais" (FLEURI, 2009, p. 25-26).

Sabe-se que a mudança nas formas de pensar e interagir se institui a partir das relações que estabelecemos com e entre os sujeitos. No Brasil, tanto pelo fato de haver uma diversidade cultural bastante ampla como também em razão da organização social dividida em classes, as demandas dos diferentes grupos socioculturais, dos movimentos sociais e das populações historicamente marginalizadas potencializam os desafios a serem enfrentados. Contudo, é importante mencionar que "[...] os processos de educação popular, desenvolvidos principalmente a partir dos movimentos populares, têm contribuído significativamente para o reconhecimento e valorização das culturas dos diferentes grupos sociais, identificados como subalternos e excluídos" (FLEURI, 2009 , p. 29). Ainda no que diz respeito aos desafios interculturais postos às instituições de ensino:

[...] faz-se necessário um olhar mais atento à questão da interculturalidade, pois com os constantes fluxos migratórios a universidade precisa se preparar para receber pessoas de culturas 
diversas para realizar a práxis intercultural. Isso porque a resistência às diferenças, no âmbito do ensino superior, é uma problemática que muitos acreditam não existir, ou fecham os olhos à sua existência, mas que está presente em todas as arenas sociais. (ALMEIDA et al., 2018, p. 154).

Tais desafios se colocam não apenas às instituições de ensino brasileiras mas também em escala mundial, visando a uma educação intercultural e inclusiva. De acordo com Espejo (2018, p. 92), pesquisador da Universidade Católica de Maule/Espanha,

La inclusión de estudiantes objeto de discriminación o exclusión social de los sistemas educativos formales, motivados por su pertenencia a pueblos originarios, minorías étnicas, migrantes, disidentes sexuales o de género, entre muchos otros aspectos, no sólo ha sido descuidada sino que muy recientemente se ha tomado conciencia acerca de sus requerimientos y, consecuentemente, de la necesidad de contar con una normativa legal que atienda a sus especificidades; así como de la preparación que requieren los profesionales de la educación que diariamente conviven con ellos en la sala de clases.

A compreensão adotada neste trabalho, convergente com a afirmação de Espejo (2018), é a de que além de construir políticas, culturas e práticas inclusivas e interculturais, torna-se indispensável desenvolver práticas pedagogicamente inovadoras. Segundo Vasconcellos e Santiago (2018, p. 38), as posturas pedagogicamente inovadoras requerem rompimento com práticas reprodutoras dos diferentes saberes e mudanças nas novas formas de nos posicionarmos diante do conhecimento.

Como é possível observar, a inovação pedagógica ultrapassa a ideia de utilização de recursos tecnológicos. A esse respeito, vale mencionar que apesar de

[...] muitos considerem que inovar seja trocar um instrumento por outro, um dispositivo obsoleto por um de última geração, entendemos que inovar, em educação, é perceber que não existe um único currículo, que não se devem praticar formas cristalizadas de avaliação, que as culturas coletivas e individuais se afetam e, também, interferem (ou deveriam interferir) nos currículos aplicados nas escolas e universidades; é necessário desenvolver um olhar capaz de detectar particularidades e necessidades educacionais ímpares. Inovamos quando quebramos paradigmas [...]. (ALMEIDA et al., 2018, p. 155).

Nessa direção, compreende-se que a inovação em educação pode ser entendida como toda a ação pedagógica comprometida com a formação integral dos sujeitos que respeite suas especificidades e potencialize sua aprendizagem. Isso significa que a 
inovação pedagógica exige "[...] uma mudança de atitude do professor, que presta muito maior atenção à criação de contextos da aprendizagem para seus alunos do que aquela que é tradicionalmente comum, centrando neles, e na atividade deles, o essencial dos processos" (FINO, 2011, p. 5).

Ainda nessa direção, defende-se que as inovações pedagógicas são ações “[...] que, essencialmente, devem ser capazes de promover o respeito aos sujeitos nas suas particularidades e nas suas potencialidades, resguardando o princípio da diferença" (FRANCO; SILVA; TORISU, 2018, p. 1324). Tal afirmação considera que:

[...] vivemos num tempo histórico que se caracteriza por inúmeras mudanças impulsionadas por novos conhecimentos e avançadas tecnologias, o que traz novos desafios e mudanças em vários ambientes, inclusive o educacional. Nessa perspectiva, podemos dizer que não basta ensinar o que é conhecido, é também necessário preparar o aluno para questionar, refletir, mudar e inventar, ou seja, para seu autoconhecimento. (CAMPANI; SILVA; PARENTE, 2018, p. 20).

Ainda conforme as autoras, “[...] a inovação pedagógica respeita as práticas sociais participativas e protagonistas emergentes na universidade. Essa é a relação democrática com o conhecimento que o currículo e o processo ensino-aprendizagem devem construir" (CAMPANI; SILVA; PARENTE, 2018, p. 20).

\section{Inclusão, interculturalidade e inovação pedagógica nos cursos de licenciatura do IFC}

Refletir sobre a importância de uma formação que contemple a inovação pedagógica e uma abordagem intercultural e inclusiva para a formação integral dos acadêmicos dos cursos de licenciatura, conforme já mencionado neste texto, tem sido objeto de preocupação por parte de gestores e professores do IFC há alguns anos. Este debate também é recorrente nos encontros do OIIIIPe, cujo diagnostico sustenta que, universalmente, há movimentos acadêmicos que têm reconhecido e trabalhado a partir dos diferentes contextos socioculturais dos estudantes, principalmente nos programas de formação de professores. Vale mencionar a este respeito que, “[...] quanto mais se democratiza o acesso ao ensino superior, sujeitos antes segregados, excluídos entram em cena como sujeitos de conhecimento" (DAMÁZIO; SANTOS, 2018, p. 1231).

Nessa direção, entendemos que: 
Se, por um lado, o Brasil caminhou adiante na direção de democratizar o acesso às universidades, de outro, o modus operandi das atividades de ensino, nessas instituições, parece andar a passos lentos e, por vezes, estagnado no tempo. As ações pedagógicas que possibilitem uma democratização das convivências, que tenham como base $\mathrm{o}$ respeito às diferenças e que questionem o paradigma racionalista do fazer pedagógico na universidade são fundamentais para a modificação do modelo vigente. (FRANCO; SILVA; TORISU, 2018, p. 1323).

Em vista disso, é cada vez mais urgente que as instituições de ensino superior realizem estudos e pesquisas problematizando as temáticas da inclusão, da interculturalidade e da inovação pedagógica. Tais estudos e pesquisas têm, portanto, o compromisso tanto de diagnosticar e refletir sobre a realidade como também de pensar e propor ações que possam contribuir para a redução dos índices de exclusão no ensino superior, que são ainda maiores do que na educação básica. A esse respeito, importa dizer que "[...] a universidade que surgiu com a intenção de formar uma elite hoje se depara com a necessidade de criar alternativas que possam responder às exigências dos grupos sociais excluídos” (CAMPANI; SILVA; PARENTE, 2018, p. 20).

Tal problemática é consenso entre educadores e gestores que atuam no ensino superior, visto que estes estão conscientes de que os estudantes encontram dificuldades de diferentes ordens para permanecer na universidade. Algumas dessas dificuldades podem ser superadas com o auxílio das instituições de ensino superior, através de ações afirmativas não apenas para o ingresso, mas fundamentalmente para a permanência, combatendo a evasão e a retenção. Nessa direção, o desenvolvimento de práticas pedagógicas inclusivas, as adaptações curriculares e os programas de auxílio para a permanência destes estudantes nos cursos superiores são essenciais.

Vale mencionar ainda que a exclusão acontece no nível superior de variadas maneiras, muitas das quais veladas (SANTOS et al., 2007), e envolve diferentes atores (professores, servidores e alunos), gerando tensões que podem se constituir em verdadeiras barreiras, divergindo de uma postura intercultural, pedagogicamente inovadora e inclusiva.

Segundo a concepção do OIIIIPe, investir em práticas pedagógicas inovadoras significa provocar rupturas paradigmáticas na docência, o que, segundo Cunha (2010), envolve algumas condições e características peculiares, entre as quais se destacam a ruptura com a forma tradicional de ensinar e aprender, a gestão participativa, a reconfiguração de saberes, a reorganização da relação teoria/prática, o processo 
avaliativo, a mediação como condição da aprendizagem significativa e o protagonismo dos estudantes na perspectiva de estimular a produção de conhecimento.

Considerando as características apresentadas por Cunha (2010), no que tange à inovação pedagógica no ensino superior, entende-se que as práticas pedagógicas inovadoras são aquelas que, entre outros aspectos, sustentam-se em uma abordagem intercultural e inclusiva. Desse modo, compreende-se que o processo de reestruturação dos PPCs dos cursos de licenciatura no IFC, ao estabelecerem um núcleo comum para a formação, que contempla tais discussões, permitem inferir que se caminha na direção da implantação e implementação de processos formativos comprometidos com a formação integral dos sujeitos. Essa afirmação leva em conta que a presença das temáticas da inclusão, da interculturalidade e da inovação pedagógica nesses cursos tem induzido também a mudança de políticas, de cultura e de práticas.

O núcleo comum das licenciaturas constitui-se dos seguintes componentes curriculares (com carga horária de 60 horas): Didática; Diversidade, Inclusão e Direitos Humanos; Educação Inclusiva; Educação, Sociedade e Trabalho; Filosofia da Educação; Gestão Educacional; História da Educação; Políticas Públicas da Educação; Psicologia da Educação; Sociologia da Educação; e Teorias Educacionais e Curriculares. Nesses componentes curriculares, observamos que as temáticas da inclusão, da interculturalidade e da inovação pedagógica estão contempladas da seguinte forma:

Quadro 1 - Componentes curriculares e itens das ementas do núcleo comum das licenciaturas do IFC que indicam a presença das temáticas da inclusão, da interculturalidade e da inovação pedagógica

\begin{tabular}{|l|l|}
\hline Componente curricular & $\begin{array}{l}\text { Itens da ementa que indicam a presença direta das temáticas da } \\
\text { inclusão, interculturalidade e inovação pedagógica }\end{array}$ \\
\hline \multirow{2}{*}{$\begin{array}{l}\text { Diversidade, Inclusão e } \\
\text { Direitos Humanos }\end{array}$} & $\begin{array}{l}\text { Educação, Ética e Direitos Humanos: a Educação como direito } \\
\text { fundamental. Os Direitos Humanos e a formação à cidadania. A } \\
\text { construção de uma educação para o respeito e para compreensão das } \\
\text { alteridades. Diversidade: preconceito, discriminação e prática educativa; } \\
\text { escola, violência e redes de proteção; diversidade e diferença. Relações }\end{array}$ \\
étnico-raciais, indígena e quilombola. A Educação Intercultural Inclusiva \\
e Legislação.
\end{tabular}




\begin{tabular}{|l|l|}
\hline História da Educação & $\begin{array}{l}\text { História da educação e as questões de gênero, étnico-raciais, indígena, } \\
\text { quilombola. }\end{array}$ \\
\hline Sociologia da Educação & $\begin{array}{l}\text { Educação e desigualdades sociais: de gênero, étnico-raciais, econômica, } \\
\text { cultural. Escola, processos educativos e processos sociais. }\end{array}$ \\
\hline $\begin{array}{l}\text { Teorias Educacionais e } \\
\text { Curriculares }\end{array}$ & $\begin{array}{l}\text { Teorias educacionais, currículo e os temas transversais: meio ambiente, } \\
\text { relações étnico-raciais, indígena e quilombola, ética e direitos humanos. } \\
\text { Organizações curriculares nos documentos oficiais. Currículo e cultura. }\end{array}$ \\
\hline
\end{tabular}

Fonte: elaborado pelas autoras a partir dos dados disponibilizados pela Pró-reitoria de Ensino.

Importa destacar também que as disciplinas de Leitura e Produção Textual (30 ou 60 horas, conforme definição de cada colegiado de curso) e Língua Brasileira de Sinais (Libras) (60 horas) são componentes obrigatórios em todos os cursos de licenciatura, embora não façam parte do núcleo comum. Toda a ementa da disciplina de Libras possui relação com as temáticas da inclusão e da interculturalidade, como é possível observar: Surdez e linguagem; Concepções do oralismo; Comunicação total e bilinguismo da educação de surdos; Alfabeto manual; Os números e o vocabulário de Libras; Professor bilíngue; Cultura e identidade dos surdos; Aspectos históricos da educação dos surdos; Vocabulário de Libras; Intérprete na sala de aula; Construção da escrita dos surdos; e Aspectos linguísticos da Libras.

Além desses componentes curriculares (do núcleo comum e os obrigatórios), observou-se na análise documental realizada que há outros que indicam a presença das discussões das temáticas mencionadas e são comuns nos cursos oferecidos em diferentes campi. Essas informações foram sistematizadas em quadros, conforme segue.

Quadro 2 - Curso de Licenciatura em Pedagogia

\begin{tabular}{|l|l|}
\hline \multicolumn{2}{|c|}{ Campi que oferecem o curso: Camboriú, Videira, Blumenau e Rio do Sul } \\
\hline \multicolumn{1}{|c|}{ Componente curricular } & \multicolumn{1}{c|}{ Itens da ementa } \\
\hline Antropologia & $\begin{array}{l}\text { As interpretaçães antropológicas da cultura e da sociedade no } \\
\text { Brasil. A crítica ao etnocentrismo e ao relativismo cultural. Etnia- } \\
\text { raça, classe social e gênero na constituição social. }\end{array}$ \\
\hline \multirow{3}{*}{$\begin{array}{l}\text { Modalidades da Educaçãoas públicas e legislação nas modalidades da Educação Básica } \\
\text { Básica I }\end{array}$} & $\begin{array}{l}\text { (Educação Especial, Educação do Campo, Educação Quilombola e } \\
\text { Educação Indígena). Trajetória da Educação Especial, Educação do } \\
\text { Campo, Educação Quilombola e Educação Indígena no Brasil. } \\
\text { Especificidades da docência nas modalidades da Educação Básica } \\
\text { (Educação Especial, Educação do Campo, Educação Quilombola e } \\
\text { Educação Indígena). }\end{array}$ \\
\hline $\begin{array}{l}\text { Modalidades da Educação } \\
\text { Básica II }\end{array}$ & $\begin{array}{l}\text { Políticas públicas e legislação nas modalidades da Educação Básica } \\
\text { (EJA e Educação Profissional Tecnológica). Trajetória da Educação } \\
\text { de Jovens e Adultos (EJA) e Educação Profissional Tecnológica no } \\
\text { Brasil. Especificidades da docência nas modalidades da Educação } \\
\text { Básica (EJA e Educação Profissional). }\end{array}$ \\
\hline
\end{tabular}




\begin{tabular}{|l|l|}
\hline Pedagogia e Profissão docente & $\begin{array}{l}\text { Práxis pedagógica e o fazer científico. Formação do pedagogo e o } \\
\text { campo de atuação profissional: contexto histórico e o papel social, } \\
\text { ético e político. }\end{array}$ \\
\hline $\begin{array}{l}\text { Pesquisa Processos } \\
\text { Educativos: I, II, III, IV, V, VI, } \\
\text { VII, VIII }\end{array}$ & $\begin{array}{l}\text { Este componente curricular transversaliza todo o curso. Na } \\
\text { regulamentação da estrutura e do funcionamento do componente } \\
\text { curricular e do próprio curso, observa-se que sua intencionalidade é } \\
\text { o ensino com pesquisa, visando formar pedagogos para e nas mais } \\
\text { diversas possibilidades de atuação aptos a investigar a realidade e a } \\
\text { buscar soluçães para as situaçôes/problemas que enfrentarão. Este } \\
\text { exercício já é realizado durante o curso e culmina em um Trabalho } \\
\text { de Conclusão. }\end{array}$ \\
\hline $\begin{array}{l}\text { Tecnologias da Informação e } \\
\text { Comunicação em educação }\end{array}$ & $\begin{array}{l}\text { Estudo teórico-prático e crítico dos recursos computacionais } \\
\text { voltados à educação (internet, multimídias, aplicativos, softwares } \\
\text { educacionais, etc.). Tecnologias de informação e comunicação } \\
\text { como recurso tecnológico no processo de ensino-aprendizagem. }\end{array}$ \\
\hline $\begin{array}{l}\text { Estágio Supervisionado } \\
\text { I e II - Educação Infantil } \\
\text { III e IV- Anos Iniciais do } \\
\text { Ensino Fundamental }\end{array}$ & $\begin{array}{l}\text { Considerando-se a característica dos componentes curriculares, que } \\
\text { possuem como principal propósito a inserção do licenciando na } \\
\text { escola, entende-se que eles possuem relação direta com as } \\
\text { discussões das temáticas da inclusão, da interculturalidade e da } \\
\text { inovação pedagógica. }\end{array}$ \\
\hline
\end{tabular}

Fonte: elaborado pelas autoras a partir dos dados disponibilizados pela Pró-reitoria de Ensino.

No que diz respeito aos cursos de Licenciatura em Pedagogia, observa-se que, em todos os seus campi de oferta, há pelo menos 23 componentes curriculares que contemplam as discussões das temáticas da inclusão, da interculturalidade e da inovação pedagógica, conforme podemos observar nos quadros 1 e 2.

\section{Quadro 3 - Curso de Licenciatura em Matemática}

\begin{tabular}{|l|l|}
\hline \multicolumn{2}{|c|}{ Campi que oferecem o curso: Camboriú, Concórdia, Rio do Sul e Sombrio } \\
\hline \multicolumn{1}{|c|}{$\begin{array}{c}\text { Componente } \\
\text { curricular }\end{array}$} & \multicolumn{1}{c|}{ Itens da ementa } \\
\hline $\begin{array}{l}\text { Estágio Supervisionado } \\
\text { I, II, III, IV }\end{array}$ & $\begin{array}{l}\text { Considerando-se a característica dos componentes curriculares, que possuem } \\
\text { como principal propósito a inserção do licenciando na escola, entende-se } \\
\text { que eles possuem relação direta com as discussões das temáticas da } \\
\text { inclusão, da interculturalidade e da inovação pedagógica. }\end{array}$ \\
\hline $\begin{array}{l}\text { Pesquisa e Processos } \\
\text { Educativos I, II, III, IV }\end{array}$ & $\begin{array}{l}\text { Este componente curricular é ofertado nos quatro primeiros semestres do } \\
\text { Curso de Licenciatura em Matemática. De acordo com a regulamentação da } \\
\text { estrutura e do funcionamento deste componente curricular, observa-se que } \\
\text { sua intencionalidade é o ensino com pesquisa, visando formar professores } \\
\text { aptos a investigar a realidade e a buscar soluções para as } \\
\text { situações/problemas que enfrentarão no exercício da docência. }\end{array}$ \\
\hline $\begin{array}{l}\text { Tecnologias Digitais } \\
\text { no Ensino } \\
\text { Matemática }\end{array}$ & $\begin{array}{l}\text { Estudo do movimento histórico da disseminação e inserção das Tecnologias } \\
\text { na Educação e na Educação Matemática. Fases das Tecnologias Digitais em } \\
\text { Educação Matemática. Cultura Digital. Internet e Educação. Ambientes } \\
\text { Virtuais de Aprendizagem. Objetos Virtuais de Aprendizagem. Softwares no } \\
\text { Ensino de Matemática. }\end{array}$ \\
\hline
\end{tabular}

Fonte: elaborado pelas autoras a partir dos dados disponibilizados pela Pró-reitoria de Ensino. 


\section{Quadro 4 - Curso de Licenciatura em Física}

\begin{tabular}{|c|c|}
\hline \multicolumn{2}{|r|}{ Campi que oferecem o curso: Concórdia e Rio do Sul } \\
\hline $\begin{array}{l}\text { Componente } \\
\text { curricular }\end{array}$ & Itens da ementa \\
\hline $\begin{array}{l}\text { Estágio Supervisionado } \\
\text { I, II e III }\end{array}$ & $\begin{array}{l}\text { Considerando-se a característica dos componentes curriculares, que possuem } \\
\text { como principal propósito a inserção do licenciando na escola, entende-se } \\
\text { que eles possuem relação direta com as discussões das temáticas da } \\
\text { inclusão, da interculturalidade e da inovação pedagógica. }\end{array}$ \\
\hline $\begin{array}{l}\text { Metodologia do ensino } \\
\text { da Física }\end{array}$ & $\begin{array}{l}\text { Conhecimentos teóricos e práticos sobre metodologias, fundamentados em } \\
\text { teorias de ensino e aprendizagem, na história e filosofia da ciência, em } \\
\text { teorias curriculares, nas práticas experimentais inovadoras e na abordagem } \\
\text { Ciência, Tecnologia e Sociedade. }\end{array}$ \\
\hline $\begin{array}{l}\text { Pesquisa e Processos } \\
\text { Educativos I, II, III, IV }\end{array}$ & $\begin{array}{l}\text { Este componente curricular é ofertado nos quatro primeiros semestres do } \\
\text { curso de licenciatura em Física. De acordo com a regulamentação da } \\
\text { estrutura e do funcionamento deste componente curricular, observa-se que } \\
\text { sua intencionalidade é o ensino com pesquisa, visando formar professores } \\
\text { aptos a investigar a realidade e a buscar soluções para as } \\
\text { situações/problemas que enfrentarão no exercício da docência. }\end{array}$ \\
\hline $\begin{array}{l}\text { Tecnologias para o } \\
\text { ensino de Física }\end{array}$ & $\begin{array}{l}\text { Tecnologias da Informação e Comunicação no ensino de Física: } \\
\text { fundamentação teórica, planejamento da utilização e implementação de } \\
\text { diferentes meios de comunicação e informação na prática pedagógica. } \\
\text { Design instrucional. }\end{array}$ \\
\hline
\end{tabular}

Fonte: elaborado pelas autoras a partir dos dados disponibilizados pela Pró-reitoria de Ensino.

\section{Quadro 5 - Curso de Licenciatura em Química}

\begin{tabular}{|c|l|}
\hline \multicolumn{1}{|c|}{$\begin{array}{c}\text { Componente } \\
\text { curricular }\end{array}$} & \multicolumn{1}{c|}{ Itens da ementa } \\
\hline $\begin{array}{l}\text { Estágio Supervisionado oferecem o curso: Araquari e Brusque } \\
\text { I, II, III, IV }\end{array}$ & $\begin{array}{l}\text { Considerando-se a característica dos componentes curriculares, que possuem } \\
\text { como principal propósito a inserção do licenciando na escola, entende-se } \\
\text { que eles possuem relação direta com as discussões das temáticas da } \\
\text { inclusão, da interculturalidade e da inovação pedagógica. }\end{array}$ \\
\hline $\begin{array}{l}\text { Tecnologias } \\
\text { Informação de } \\
\text { Comunicação em } \\
\text { educação }\end{array}$ & $\begin{array}{l}\text { Alfabetização científica e tecnológica. Tecnologia Educacional. Design } \\
\text { Instrucional. O uso das Tecnologias da Informação e Comunicação (TIC) no } \\
\text { processo ensino-aprendizagem. Implicações do uso das TIC na Educação. } \\
\text { Visão histórica das TIC na Educação. Integração das diferentes tecnologias } \\
\text { existentes no processo de ensino. Teorias estratégias de aprendizagem. } \\
\text { Construção do conhecimento por meio do uso de TIC. }\end{array}$ \\
\hline $\begin{array}{l}\text { Pesquisa e Processos } \\
\text { Educativos I, II, III, IV }\end{array}$ & $\begin{array}{l}\text { Este componente curricular é ofertado nos quatro primeiros semestres do } \\
\text { curso de licenciatura em Química. De acordo com a regulamentação da } \\
\text { estrutura e do funcionamento deste componente curricular, observa-se que } \\
\text { sua intencionalidade é o ensino com pesquisa, visando formar professores } \\
\text { aptos a investigar a realidade e a buscar soluções para as } \\
\text { situações/problemas que enfrentarão no exercício da docência. }\end{array}$ \\
\hline
\end{tabular}

Fonte: elaborado pelas autoras a partir dos dados disponibilizados pela Pró-reitoria de Ensino.

Quanto aos cursos de Licenciatura em Matemática e Física, observa-se que, em todos os seus campi de oferta, há pelo menos 14 componentes curriculares que 
contemplam as discussões das temáticas da inclusão, da interculturalidade e da inovação pedagógica (quadros 1, 3 e 4). Já no curso de Licenciatura em Química, ofertado nos campi de Brusque e Araquari temos 13 componentes curriculares que abordam as temáticas mencionadas (quadros 1 e 5).

\section{Quadro 6 - Curso de Licenciatura em Ciências Agrícolas (continua)}

\begin{tabular}{|l|l|}
\hline \multicolumn{2}{|c|}{ Campus que oferta o curso: Araquari } \\
\hline Componente curricular & \multicolumn{1}{c|}{ Itens da ementa } \\
\hline $\begin{array}{l}\text { Pesquisa e Processos } \\
\text { Educativos I, II, III, IV }\end{array}$ & $\begin{array}{l}\text { Este componente curricular é ofertado nos quatro primeiros semestres do } \\
\text { curso de licenciatura em Ciências Agrícolas. De acordo com a } \\
\text { regulamentação da estrutura e do funcionamento deste componente } \\
\text { visando formar professores aptos a investigar a realidade e a buscar } \\
\text { soluções para as situações/problemas que enfrentarão no exercício da } \\
\text { docência. }\end{array}$ \\
\hline \multirow{5}{*}{$\begin{array}{l}\text { Didática do Ensino de } \\
\text { Ciências Agrárias }\end{array}$} & $\begin{array}{l}\text { Discussões acerca dos métodos necessários para o desenvolvimento } \\
\text { didático do profissional licenciado em Ciências Agrárias visando à } \\
\text { capacitação técnica-pedagógica, para serem aplicados no ensino, na } \\
\text { pesquisa e na extensão, em ambientes formais e informais, oportunizando } \\
\text { vivências necessárias para o diálogo teórico e prático, na percepção da } \\
\text { Educação no Campo, para comunidades tradicionais, escolas familiares } \\
\text { rurais, no ensino agrotécnico e ambiental de nível fundamental e médio e } \\
\text { no ensino em instituições de ensino superior. Análise do discurso técnico- } \\
\text { pedagógico para a formação técnica e profissional no campo das Ciências } \\
\text { Agrárias, considerando aspectos multiculturais, sociais, ambientais e } \\
\text { econômicos. }\end{array}$ \\
\hline
\end{tabular}

Fonte: Fonte: elaborado pelas autoras a partir dos dados disponibilizados pela Pró-reitoria de Ensino.

Quadro 6 - Curso de Licenciatura em Ciências Agrícolas (conclusão)

\begin{tabular}{|l|l|}
\hline \multicolumn{2}{|c|}{ Campus que oferta o curso: Araquari } \\
\hline Componente curricular & \multicolumn{1}{c|}{ Itens da ementa } \\
\hline $\begin{array}{l}\text { Estágio Supervisionado } \\
\text { I, II, III e IV }\end{array}$ & $\begin{array}{l}\text { Considerando-se a característica dos componentes curriculares, que } \\
\text { possuem como principal propósito a inserção do licenciando na escola, } \\
\text { entende-se que eles possuem relação direta com as discussões das } \\
\text { temáticas da inclusão, da interculturalidade e da inovação pedagógica. }\end{array}$ \\
\hline Extensão Rural & $\begin{array}{l}\text { Abordagens sobre o ensino da extensão rural. Histórico, conceitos e } \\
\text { objetivos da construção e do desenvolvimento rural comunitário. } \\
\text { Planejamentos e ações a partir da metodologia participativa. Processos } \\
\text { educacionais que visam à aprendizagem e à aplicação de técnicas } \\
\text { extensionistas perante a diversidade sociocultural. Pesquisa e extensão } \\
\text { rural em direção à modernização do campo. Estudos de casos sobre a } \\
\text { extensão rural e o desenvolvimento rural: aplicações práticas. }\end{array}$ \\
\hline $\begin{array}{l}\text { Sociedades } \\
\text { Subjetividades em } \\
\text { Contextos Rurais }\end{array}$ & $\begin{array}{l}\text { Formação e desenvolvimento da sociedade rural brasileira. As relaçães } \\
\text { sociais no campo e as interações entre rural e urbano. Pobreza, exclusão e } \\
\text { relevância do capital humano no mundo rural. Visibilidade e intervenções } \\
\text { voltadas para ensino, pesquisa e extensão em um campo não apenas como } \\
\text { território de negócios, mas em constante processo construtivo de relações } \\
\text { sociais. Subjetividade e educação na sociedade rural. }\end{array}$ \\
\hline
\end{tabular}

Fonte: elaborado pelas autoras a partir dos dados disponibilizados pela Pró-reitoria de Ensino. 
No que tange aos cursos de Licenciatura em Ciências Agrícolas, observa-se que, em todos os seus campi de oferta, há pelo menos 16 componentes curriculares que contemplam as discussões das temáticas da inclusão, da interculturalidade e da inovação pedagógica (quadros 1 e 6 ).

Quadro 7 - Curso de Licenciatura em Pedagogia com ênfase em Educação do Campo (continua)

\begin{tabular}{|l|l|}
\hline \multicolumn{1}{|c|}{ Campus de oferta: Abelardo Luz } \\
\hline Componente curricular & \multicolumn{1}{c|}{ Itens da ementa } \\
\hline Antropologia & $\begin{array}{l}\text { A constituição da Antropologia como disciplina e seu campo de estudo. } \\
\text { As interpretações antropológicas da cultura e da sociedade no Brasil. A } \\
\text { crítica ao etnocentrismo e ao relativismo cultural. Etnia-raça, classe } \\
\text { social e gênero na constituição social. Estudos antropológicos sobre } \\
\text { educação e a escola no Brasil. Concepçôes de família/criança/infância } \\
\text { como construção histórica/social e seu papel na Educação. }\end{array}$ \\
\hline Seminário Integrador I & $\begin{array}{l}\text { Estudo do PPC do curso. Levantamento e caracterização dos espaços de } \\
\text { inserção (escola e comunidade). Planejamento e orientação para os } \\
\text { processos de inserção e os estudos sistemáticos. }\end{array}$ \\
\hline Seminário Integrador II & $\begin{array}{l}\text { Estudo do método de intervenção e trabalho de base em comunidades } \\
\text { camponesas e dos processos de inserção na escola. Estabelecimento de } \\
\text { relações entre as diferentes disciplinas do curso e de processos de } \\
\text { investigação da realidade escolar e não escolar, em seus aspectos } \\
\text { sociopedagógicos. Elaboração de síntese e planejamento sobre o } \\
\text { processo de inserção na escola e na comunidade. }\end{array}$ \\
\hline
\end{tabular}

Fonte: elaborado pelas autoras a partir dos dados disponibilizados pela Pró-reitoria de Ensino.

Quadro 7 - Curso de Licenciatura em Pedagogia com ênfase em Educação do Campo (continuação)

\begin{tabular}{|l|l|}
\hline \multicolumn{1}{|c|}{ Campus de oferta: Abelardo Luz } \\
\hline Componente curricular & \multicolumn{1}{|c|}{ Itens da ementa } \\
\hline Seminário Integrador III & $\begin{array}{l}\text { Construção de análises e sínteses a partir da problematização de questões } \\
\text { trabalhadas em diferentes disciplinas do curso e de processos de } \\
\text { investigação da realidade, em seus aspectos sociopedagógicos. } \\
\text { Desenvolvimento de estratégias de discussão e de levantamentos de } \\
\text { demandas nos espaços de inserção, na escola e na comunidade. } \\
\text { Realização de processos orientados de inserção. }\end{array}$ \\
\hline Seminário Integrador IV & $\begin{array}{l}\text { Organização de sínteses a partir de questões trabalhadas em diferentes } \\
\text { disciplinas do curso e de processos de investigação da realidade, em seus } \\
\text { aspectos sociopedagógicos. Orientação para organização de dados } \\
\text { coletados na comunidade e na escola. }\end{array}$ \\
\hline Seminário Integrador V & $\begin{array}{l}\text { Construção de processos analíticos sobre questões trabalhadas em } \\
\text { diferentes disciplinas do curso e de processos de investigação da } \\
\text { realidade, em seus aspectos sociopedagógicos. Planejamento e } \\
\text { orientação para os processos de inserção na escola e na comunidade e }\end{array}$ \\
\hline
\end{tabular}




\begin{tabular}{|c|c|}
\hline & $\begin{array}{l}\text { para estudos sistemáticos. Realização de processos orientados de } \\
\text { inserção na comunidade e na escola. }\end{array}$ \\
\hline Seminário Integrador VI & $\begin{array}{l}\text { Construção de análises e sínteses a partir da problematização de questões } \\
\text { trabalhadas em diferentes disciplinas do curso e de processos de } \\
\text { investigação da realidade, em seus aspectos sociopedagógicos. } \\
\text { Investigação sobre processos educativos escolares e comunitários. }\end{array}$ \\
\hline Seminário Integrador VII & $\begin{array}{l}\text { Construção de sínteses a partir de questões trabalhadas em diferentes } \\
\text { disciplinas do curso e em processos de investigação da realidade, em } \\
\text { seus aspectos sociopedagógicos. Organização dos resultados obtidos nos } \\
\text { processos de inserção na escola e na comunidade. }\end{array}$ \\
\hline Seminário Integrador VIII & $\begin{array}{l}\text { Organização dos resultados obtidos nos processos de inserção na escola } \\
\text { e na comunidade. }\end{array}$ \\
\hline $\begin{array}{l}\text { Pedagogia e Profissão } \\
\text { Docente }\end{array}$ & $\begin{array}{l}\text { Práxis pedagógica e o fazer científico. Formação do pedagogo e o } \\
\text { campo de atuação profissional: contexto histórico e o papel social, ético } \\
\text { e político. }\end{array}$ \\
\hline $\begin{array}{l}\text { Pesquisa e Processos } \\
\text { Educativos I, II, III, IV }\end{array}$ & $\begin{array}{l}\text { Considerando-se a característica dos componentes curriculares, que } \\
\text { possuem como principal propósito a inserção do licenciando na escola, } \\
\text { entende-se que eles possuem relação direta com as discussões das } \\
\text { temáticas da inclusão, da interculturalidade e da inovação pedagógica. }\end{array}$ \\
\hline $\begin{array}{l}\text { Educação do Campo III: } \\
\text { História da Educação do } \\
\text { Campo e Movimentos } \\
\text { Sociais }\end{array}$ & $\begin{array}{l}\text { Origem dos movimentos sociais e movimentos sociais do campo. } \\
\text { Experiências de educação dos movimentos sociais. Educação do Campo. } \\
\text { Educação Rural. Educação Popular. Fundamentos da Educação do } \\
\text { Campo. }\end{array}$ \\
\hline $\begin{array}{l}\text { Tecnologias Digitais da } \\
\text { Informação } \\
\text { Comunicação }\end{array}$ & $\begin{array}{l}\text { Tecnologia Educacional. Recursos Audiovisuais. Mídia Impressa. } \\
\text { Internet. Software Educacional. Oficinas de Informática. }\end{array}$ \\
\hline $\begin{array}{l}\text { Gestão em espaços não } \\
\text { escolares }\end{array}$ & $\begin{array}{l}\text { Desenvolvimento do conceito sobre a função do pedagogo na } \\
\text { organização do trabalho pedagógico em espaços formativos e } \\
\text { organizativos, nas comunidades do campo e na organização de processos } \\
\text { educativos não formais. Estabelecimento de relações conceituais entre a } \\
\text { Educação Popular, a Educação do Campo e a formação. A discussão da } \\
\text { Pedagogia Social e sua função educativa em instituições não escolares. }\end{array}$ \\
\hline $\begin{array}{l}\text { Educação de Jovens e } \\
\text { Adultos }\end{array}$ & $\begin{array}{l}\text { Trajetória histórica da Educação de Jovens e Adultos (EJA). Teoria e } \\
\text { prática na EJA. Práticas curriculares e avaliativas na } \\
\text { Especificidades dos alunos de EJA. }\end{array}$ \\
\hline $\begin{array}{l}\text { Estágios Supervisionados: } \\
\text { I: Educação Infantil } \\
\text { II: Gestão escolar } \\
\text { III: Anos Iniciais do } \\
\text { Ensino Fundamental } \\
\text { IV: Gestão Educacional } \\
\text { em espaços comunitários } \\
\text { do campo }\end{array}$ & $\begin{array}{l}\text { Considerando-se a característica dos componentes curriculares, que } \\
\text { possuem como principal propósito a inserção do licenciando na escola, } \\
\text { entende-se que eles possuem relação direta com as discussões das } \\
\text { temáticas da inclusão, da interculturalidade e da inovação pedagógica. }\end{array}$ \\
\hline
\end{tabular}

Fonte: elaborado pelas autoras a partir dos dados disponibilizados no site do IFC-Campus Abelardo Luz.

\section{Com relação ao curso de Licenciatura em Pedagogia com ênfase em Educação}

do Campo, ofertado no Campus de Abelardo Luz, observa-se que há pelo menos 26 componentes curriculares que contemplam as discussões das temáticas da inclusão, da interculturalidade e da inovação pedagógica. 
Os dados coletados e apresentados neste texto nos permitem inferir que, em todos os cursos de licenciatura do IFC, a discussão da inclusão, da interculturalidade e da inovação pedagógica se faz presente, em maior ou menor grau. Observa-se pelos dados que o Curso de Pedagogia com ênfase em Educação do Campo se destaca nessas discussões, seguido dos de Pedagogia e de Ciências Agrícolas.

Entende-se ainda que a instituição de um núcleo comum aos componentes curriculares de Libras e de Pesquisa e Processos Educativos para as licenciaturas pode ser considerado um avanço em direção a uma formação que tenha como propósito a formação integral dos licenciandos. Uma formação que ultrapasse a ideia do domínio das ciências e da técnica, mas que envolva todas as dimensões da vida humana, abrangendo a ética, a estética, a compreensão dos contextos sociais, culturais, políticos, econômicos e educacionais.

Quanto a este mapeamento, cumpre mencionar que uma educação inclusiva, intercultural e pedagogicamente inovadora não se reduz às matrizes curriculares dos cursos e suas ementas. Contudo, sem a definição explícita dos elementos que compõem a formação do estudante, será impossível instituir mudanças nas concepções e práticas tanto dos formadores quanto dos estudantes, que serão futuros professores da educação básica.

Em que pese os objetivos dos cursos de licenciatura, afere-se, resumidamente, que entre eles há em comum o propósito de formar educadores emancipados, cuja prática profissional ocorra na perspectiva crítica, articulada com a inovação, com a interculturalidade e com a inclusão.

No que diz respeito aos perfis dos egressos dos cursos de licenciatura do IFC, observa-se que, ao final do curso, estes deverão ter desenvolvido conhecimentos pedagógicos, sociopolíticos, técnico-científicos e os específicos das suas áreas de atuação. Além disso, há a indicação de que o egresso deverá ter um perfil de professor pesquisador crítico-reflexivo, habilitado para atuar no ensino e na pesquisa, na organização e na gestão de projetos educacionais e na produção e difusão do conhecimento, em diversas áreas da educação.

\section{Considerações finais}

Ao finalizar este artigo, após um intenso trabalho de leitura dos projetos pedagógicos dos cursos de licenciatura do IFC e das produções teóricas dos 
pesquisadores do OIIIIPe, chega-se à conclusão de que o diálogo institucional e interinstitucional, em um movimento constante de ação-reflexão-ação, tem contribuído significativamente para que se avance na construção de currículos, de culturas e de práticas comprometidas com aqueles que historicamente são subalternizados.

Dessa compreensão, que vem provocando reflexões e, em alguma medida, desconfortos entre os envolvidos no processo educativo, passa-se à percepção de que romper com políticas e práticas que reforçam preconceitos e injustiças é um caminho sem volta quando se tem como propósito a formação integral dos estudantes e a busca de uma sociedade mais justa. Este é o caminho, esta é a luta, isto é o que nos move.

Por fim, importa mencionar que o desafio a vencer está justamente em transformar textos políticos em culturas e práticas pedagógicas voltadas para a formação integral dos estudantes. Desse modo, conforme menciona Paulo Freire (1996), o esforço está em diminuir a distância entre o discurso e a prática, ou seja, entre o que escrevemos ou defendemos e o que realmente fazemos. Daí a importância de compreender que não basta contemplar nos PPCs as temáticas da educação inclusiva, intercultural e da inovação pedagógica. Isso, por si só, não garante que as práticas representem efetivamente estas concepções; sobretudo, importa assumir o compromisso ético e político de transpor em ações aquilo que escrevemos e verbalizamos.

AGRADECIMENTOS: Agradecemos ao Instituto Federal de Educação, Ciência e Tecnologia, que financiou esta pesquisa.

\section{REFERÊNCIAS}

ALMEIDA, M. S. N. C. et al. Acessibilidade e permanência no Ensino Superior: uma análise sobre inclusão, interculturalidade e inovação pedagógica na UERJ e na UFRJ. Revista Educação e Fronteiras On-Line, Dourados/MS, v. 8, n. 22, p. 147-596, jan./abr. 2018. Disponível em: https://bit.ly/32ghhKO. Acesso em: 20 jan. 2019.

BRASIL. Ministério da Educação. Acordo de metas e compromissos. 2008. Disponível em: http://ifc.edu.br/wp-content/uploads/2014/10/MEC-SETEC-ACORDODE-METAS-E-COMPROMISSOS.pdf. Acesso em: 20 jun. 2019.

CAMPANI, A.; SILVA, M. G.; PARENTE, P. M. M. Inovação pedagógica na universidade. Revista Educação e Fronteiras On-Line, Dourados/MS, v. 8, n. 22, p. 18-34, jan./abr. 2018. Disponível em: https://bit.ly/32ghhKO. Acesso em: 20 dez. 2018.

CAPELLINI, V. L. M. F.; MACENA, J. O. A diversidade cultural na formação e 
atuação de professores. Revista Educação e Fronteiras On-Line, Dourados/MS, v. 8, n. 22, p. 160-176, jan./abr. 2018. Disponível em: https://bit.ly/32ghhKO. Acesso em: 20 dez. 2018.

CUNHA, M. I. O professor universitário na transição de paradigmas. 3. ed. Araraquara: Junqueira \& Marin editores, 2010.

DAMÁZIO, M. F. M. Educação especial na perspectiva inclusiva e o serviço do atendimento educacional especializado: da escola à universidade. Revista Educação e Fronteiras On-Line, Dourados/MS, v. 8, n. 22, p. 131-146, jan./abr. 2018. Disponível em: https://bit.ly/32ghhKO. Acesso em: 20 dez. 2018.

DAMÁZIO, M. F. M.; SANTOS, M. P. Retratos da Educação Superior - Inclusão, Interculturalidade e Inovação Pedagógica. Revista Ibero-Americana de Estudos em Educação, Araraquara, v. 13, n. esp. 2, p. 1226-1235, set. 2018. Disponível em https://bit.ly/2JoYGDF. Acesso em: 15 dez. 2018.

ESPEJO, J. C. Formação de professores e inclusão educacional na Universidade Católica de Maule. Revista Educação e Fronteiras On-Line, Dourados/MS, v. 8, n. 22, p. 88-114, jan./abr. 2018. Disponível em: https://bit.ly/32ghhKO. Acesso em: 20 dez. 2018.

FINO, C. M. N. Investigação e inovação (em educação). In: FINO, C. M. N.; SOUSA, Jesus Maria (org.). Pesquisar para mudar (a educação). Funchal: Universidade da Madeira CIE-Uma, 2011. p. 29-48. Disponível em: https://bit.ly/2JoAlxx. Acesso em: 22 jan. 2019.

FLEURI, R. M. Educação para a diversidade e cidadania: módulo 2. Florianópolis: UFSC, 2009.

FREIRE, P. Pedagogia da autonomia: saberes necessários à prática educativa. São Paulo: Paz e Terra, 1996. (Col. Leitura).

FRANCO, M. A. M.; SILVA, M. M.; TORISU, E. M. Inclusão e inovação pedagógica: políticas e práticas de formação no Ensino Superior. Revista Ibero-Americana de Estudos em Educação, Araraquara, v. 13, n. esp. 2, p. 1320-1333, set. 2018. ISSN: 1982-5587. DOI: 10.21723/riaee.v13.nesp2.set2018.11646.

LUDWIG, A. C. W. Fundamentos e prática de metodologia científica. 3. ed. Rio de Janeiro: Vozes, 2015.

INSTITUTO FEDERAL CATARINENSE ABERLADO LUZ. Projeto Pedagógico do Curso de Licenciatura em Pedagogia - Campus Abelardo Luz. Aberlado Luz, 2017. Mimeo.

INSTITUTO FEDERAL CATARINENSE ARAQUARI. Projeto Pedagógico do Curso de Licenciatura em Ciências Agrícolas - Campus Araquari. Araquari, 2017a. Mimeo.

INSTITUTO FEDERAL CATARINENSE ARAQUARI. Projeto Pedagógico do 
Curso de Licenciatura em Química - Campus Araquari. Araquari, 2017b. Mimeo.

INSTITUTO FEDERAL CATARINENSE BLUMENAU. Plano de Desenvolvimento Institucional: 2014-2018. Blumenau, 2014. Mimeo.

INSTITUTO FEDERAL CATARINENSE BLUMENAU. Projeto Pedagógico do Curso de Licenciatura em Pedagogia - Campus Blumenau. Blumenau, 2017. Mimeo.

INSTITUTO FEDERAL CATARINENSE BRUSQUE. Projeto Pedagógico do Curso de Licenciatura em Química - Campus Brusque. Brusque, 2017. Mimeo.

INSTITUTO FEDERAL CATARINENSE CAMBORIÚ. Projeto Pedagógico do Curso de Licenciatura em Matemática - Campus Camboriú. Camboriú, 2017a. Mimeo.

INSTITUTO FEDERAL CATARINENSE CAMBORIÚ. Projeto Pedagógico do Curso de Licenciatura em Pedagogia - Campus Camboriú. Camboriú, 2017b. Mimeo.

INSTITUTO FEDERAL CATARINENSE CONCÓRDIA. Projeto Pedagógico do Curso de Licenciatura em Matemática - Campus Concórdia. Concórdia, 2017a. Mimeo.

INSTITUTO FEDERAL CATARINENSE CONCÓRDIA. Projeto Pedagógico do Curso de Licenciatura em Física - Campus Concórdia. Concórdia, 2017b. Mimeo.

INSTITUTO FEDERAL CATARINENSE RIO DO SUL. Projeto Pedagógico do Curso de Licenciatura em Matemática - Campus Rio do Sul. Rio do Sul, 2017a. Mimeo.

INSTITUTO FEDERAL CATARINENSE RIO DO SUL. Projeto Pedagógico do Curso de Licenciatura em Física - Campus Rio do Sul. Rio do Sul, 2017b. Mimeo.

INSTITUTO FEDERAL CATARINENSE SOMBRIO. Projeto Pedagógico do Curso de Licenciatura em Matemática - Campus Sombrio. Sombrio, 2017. Mimeo.

INSTITUTO FEDERAL CATARINENSE VIDEIRA. Projeto Pedagógico do Curso de Licenciatura em Pedagogia - Campus Videira. Videira, 2017. Mimeo.

INSTITUTO FEDERAL CATARINENSE. Licenciaturas no IFC. Blumenau, [2018]. Disponível em: https://bit.ly/2KTFMYJ. Acesso em: 20 nov. 2018.

INSTITUTO FEDERAL CATARINENSE. Plano de Desenvolvimento Institucional do Instituto Federal Catarinense. Blumenau, [2014]. Disponível em:

http://ifc.edu.br/wp-content/uploads/2014/05/PDI_IFC.pdf. Acesso em: 20 jan. 2019.

OBSERVATÓRIO INTERNACIONAL DE INCLUSÃO, INTERCULTURALIDADE E INOVAÇÃO PEDAGÓGICA. Projeto de Pesquisa: Formação de educadores inclusão, interculturalidade e inovação pedagógica em contextos internacionais de ensino superior. 2016. 
SANTOS, M. P. dos et al. Ressignificando a formação de professores para uma educação inclusiva. Relatório final de pesquisa apresentado à Capes. Rio de Janeiro: LaPEADE/UFRJ, 2007.

SILVA, F. L. G. R.; FERNANDES, S. R. S.; FLEURI, R. M. Inclusão, interculturalidade e inovação pedagógica: problematização de práticas e de percepções de docentes, discentes e coordenadores. Revista Ibero-Americana de Estudos em Educação, Araraquara, v. 13, n. esp. 2, p. 1265-1280, set. 2018. Disponível em: https://bit.ly/2Lx1KjH. Acesso em: 20 nov. 2018.

VASCONCELLOS, M.; SANTIAGO, M. Grupo de pesquisa "Formar": inovação ou reinvenção de saberes? Revista Educação e Fronteiras On-Line, Dourados/MS, v. 8, n. 22, p. 35-46, jan./abr. 2018. Disponível em: https://bit.ly/32ghhKO. Acesso em: 20 dez. 2018.

\section{Como referenciar este artigo}

SILVA, Filomena Lucia Gossler Rodrigues; FERNANDES, Sônia Regina de Souza; LANGE, Anelise Nascimento. Inclusão, interculturalidade e inovação pedagógica nos cursos de licenciatura do instituto federal de educação, ciência e tecnologia catarinense. Revista on line de Política e Gestão Educacional, Araraquara, v. 23, n. esp. 1, p. 914935, out. 2019. E-ISSN:1519-9029. DOI: https://doi.org/10.22633/rpge.v23iesp.1.13009

\section{Submetido em: 10/05/2019}

Revisões requeridas: 14/06/2019

Aprovado em: 10/08/2019

Publicado em: 01/10/2019 